\title{
India's scientific publication in predatory journals: need for regulating quality of Indian science and education
}

\author{
G. S. Seethapathy*, J. U. Santhosh Kumar and A. S. Hareesha
}

Nature Index analysis 2014 rates India at the 13th place for its high-quality scientific publications. Despite this achievement, several studies have revealed that India is also among the major contributors of articles published in poor-quality predatory open access journals. Therefore, the objective of the present study was to estimate which category of educational and research institutes predominately publishes in predatory open access journals in India and to understand whether academicians in India are aware of predatory journals. It was found that private/government colleges contribute to about $51 \%$ of predatory publications, followed by private universities, state universities, national institutes, central universities and industries, for research articles published from September 2015 to mid-February 2016. The publication pressure among researchers and lack of monitoring the research being conducted are the major factors contributing to articles published in poor-quality predatory open access journals from India.

Keywords: Open access, scientific publishing, predatory journals, quality regulation.

RESEARCH is a self-motivated creative work undertaken by researchers on a systematic basis in order to seek answers to questions that arise in their minds. The results of such studies are published in scholarly journals primarily to share the new findings with a larger peer group and ultimately to increase the stock of knowledge. History of academic publishing dates back to the 17th century; Philosophical Transactions is the world's first science journal ${ }^{1}$. Since then, the number of referred academic journals varies from 24,000 to 29,000 as of 2014 , and is growing each year ${ }^{2}$. Academic journals/publishers can be classified into two main types: journals owned and controlled by 'non-profit' professional societies, and those owned and controlled by profit-motivated commercial publishers ${ }^{3}$. In order to cover publishing costs during the publishing process by academic publishers, the mode of publication in a journal is broadly categorized into two models: 'reader pays model' and 'author-side pays model'. Reader pays is the traditional model of publication in which the publishers obtain their revenues from

G. S. Seethapathy is in the School of Pharmacy, Department of Pharmaceutical Chemistry, University of Oslo, P.O. Box 1068 Blindern, 0316 Oslo, Norway; J. U. Santhosh Kumar is in the Department of Post Graduate Studies and Research in Biotechnology, Jnanasahyadri, Kuvempu University, Shankaraghatta, Shimoga 577451 (also in GKVK, Bengaluru), India; A. S. Hareesha are in the School of Ecology and Conservation, University of Agricultural Sciences, GKVK, Bengaluru 560 065, India.

*For correspondence. (e-mail: g.s.seethapathy@farmasi.uio.no) subscription fees charged to libraries and individual users $^{3}$. Author-side pays is a relatively new model which has developed due to the combination of advancement in internet and open access (OA) movement. In this model, the publishers obtain their revenues through article processing charges from the authors who pay to make their articles OA to everybody ${ }^{3,4}$. Publication for-free in OA journals is also possible . $^{4}$.

Although several models exist for publication, their peer-review practices, layout indexing, etc. remain largely the same. The major difference would be that OA journals are published mostly in an electronic format and submission to publication is less time-consuming than traditional scholarly journals. However, the dark side of $\mathrm{OA}$ is alarming in the name of predatory journals/ predatory publishers ${ }^{5}$.

\section{Identifying predatory journals and publishers}

Jeffrey Beall (a library scientist at the University of Colorado, Denver, USA) coined the term 'predatory publishers' to describe publishers in the scholarly publishing business who collect article processing charges and provide rapid publishing without a proper peer-review process $^{6}$. Another term 'pseudo-journals' was also suggested. To separate this sort of predatory journals from peer-reviewed journals, Beall defined a list of criteria and suggested predatory publishers and journals can usually be characterized by their constant submission of spam 
e-mails to the researchers in order to solicit new paper submission. Additionally, the name of a predatory journal is often misleading with strong preference to start with 'American', 'European' or 'International'; such publishers use e-mail addresses that end in gmail.com, yahoo.com or other free e-mails. This list is rather long with 48 criteria which directly or indirectly indicate whether the publisher and individual journal is predatory ${ }^{7}$.

\section{Contrasting Indian scientific publications}

India has a long history of scientific excellence, progress in scientific research and science education. A new analytic database called 'Nature Index' launched in 2014 by the Nature Publishing Group has highlighted that India's research outputs have grown steadily since 2012 and that the country ranks 13 th for its high-quality scientific publications in an independently selected group of 68 highquality scientific journals ${ }^{8}$. Nevertheless, several studies have revealed that India is among the major contributors of articles published in poor-quality predatory OA journals ${ }^{9-11}$. Thus there is a duality in scientific publishing in India. The specific objectives of the present study are: (i) To estimate which category of educational and research institutes predominately publishes in predatory OA journals in India. (ii) To understand whether academicians in India are aware of predatory journals and what motivates them to publish in such poor-quality predatory journals.

\section{Methodology}

\section{Sampling and data collection}

As of 15 February 2016, Beall's list contains 958 items on predatory publishers and 935 items on predatory journals. Since it would take a lot of efforts to manually check all the articles published in all the predatory journals catalogued by Beall, we randomly downloaded 1015 articles per journal published during September 2015 to mid-February 2016. A total of 3300 articles from 350 journals were downloaded irrespective of any academic discipline. From the downloaded articles, details of the corresponding author (i.e. author e-mail ID and affiliation), name of the journal, ISSN number of the journal and funding agencies, if any, that have been mentioned in the acknowledgement of the article were documented (Figure 1).

In order to classify the corresponding author's affiliation, we considered the list of all Indian higher educational institutes from the University Grants Commission (UGC) website (http://www.ugc.ac.in/) and segregated them into Central Universities, State Universities, private universities and colleges (deemed universities), and Government colleges. Next, the research institutes were segregated into several categories such as Council of Sci- entific and Industrial Research (CSIR) institutes, Indian Council of Agricultural Research (ICAR) institutes, National Institutes of Technology (NITs), Indian Institutes of Technology (IITs), Indian Council of Medical Research (ICMR) institutes and other national research institutes. Private companies and industries were also segregated. Next we assigned each corresponding author's affiliation to one of these categories, to gain insight into the distribution of authors who have published in predatory journals across various types of academic and research institutes. In order to find the distribution of authors, we calculated the total number of predatory publications in terms of each categorized higher educational institute using details of corresponding author affiliation which were collected from 3300 articles of 350 journals, irrespective of their scientific discipline (Figure 1).

\section{Online questionnaire and data analysis}

In order to find whether academicians/researchers in India are aware of predatory journals, what motivates them to publish in such poor-quality journals and how they get funding to pay for publications (article processing charges), an on-line questionnaire was sent to 2000 corresponding authors publishing in predatory journals with details of informed consent, background of the study and other relevant details (see Supplementary material online). However, a major setback in the on-line survey was that we only got 480 responses to the questionnaire. Using these responses, the respondents were categorized according to their academic position and academic discipline (Figure 1). Further, descriptive statistics was used to represent the overall responses from the questionnaire related to predatory journals.

\section{Results and discussion}

Our findings show that at present a large section of the country's public research is concentrated in national research centres as well as in a few central and state universities. These major government academic institutions are capable of producing high-quality scientific research and publications. Such publications have been considered by the Nature Index, which has placed India among the high-quality scientific publishers in the world.

However, apart from these national institutes, India is also home to a large number of private universities, private deemed universities and private and government colleges affiliated to central or state universities. (From now on we will refer to these educational institutes as second-level academic institutes in India.) Figure 2 illustrates that these second-level academic institutes have published more in poor-quality OA predatory journals, which in turn makes India among the biggest contributors of predatory articles. From our data, it is evident that the 


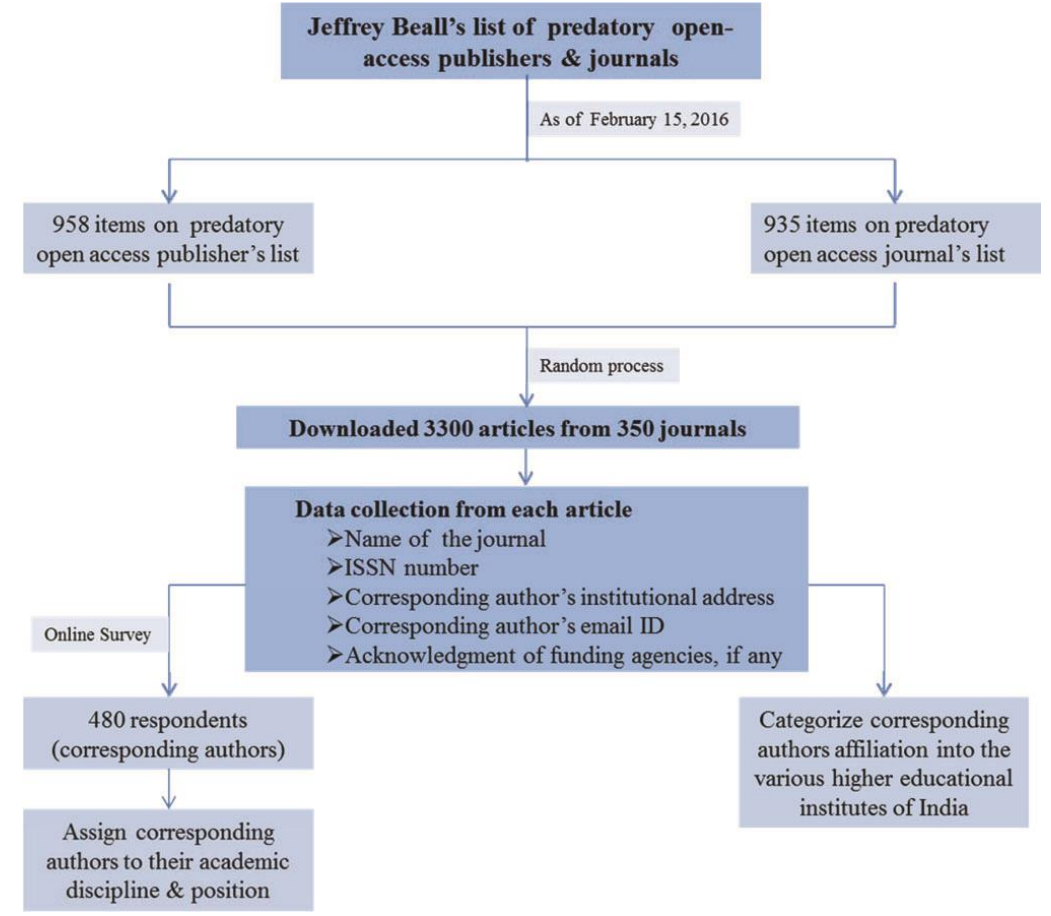

Figure 1. Sampling process.

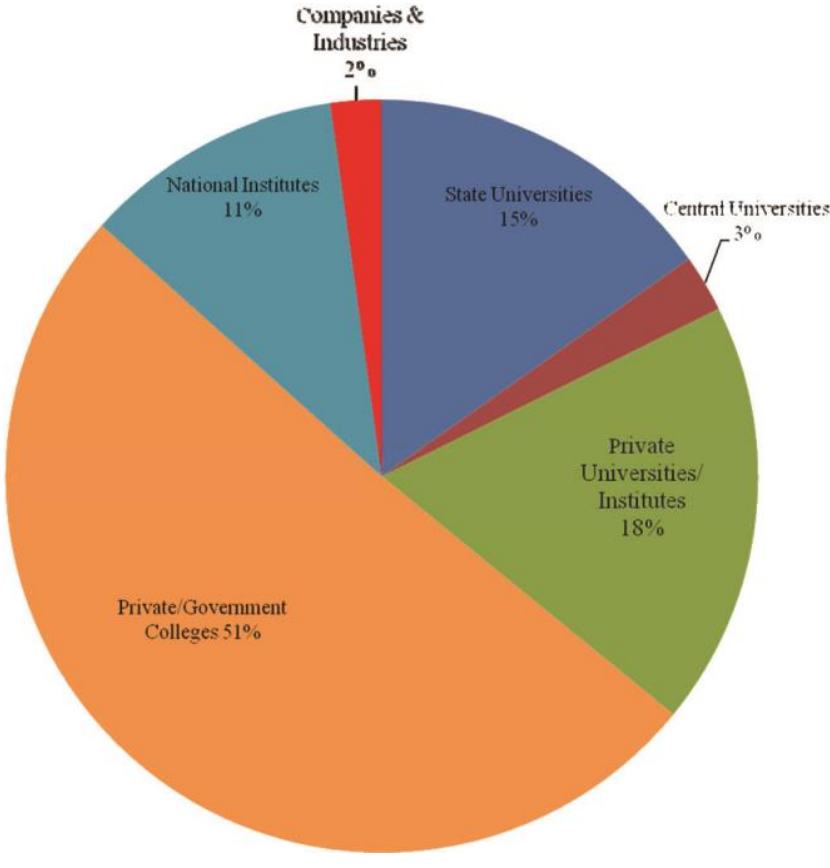

Figure 2. Distribution of corresponding authors in predatory journals from various higher educational and research institutes in India.

colleges affiliated to universities as well as autonomous colleges contribute to about $51 \%$ of predatory publications. This suggests that research conducted at these educational institutes is not critically monitored either by the respective university or by UGC. In comparison, wellranked private universities, state and central universities contribute $18 \%, 15 \%$ and $3 \%$ respectively, in predatory publications.

Shen and Björk ${ }^{11}$ have shown that $35 \%$ of publications in predatory journals is by Indians. Our data reveals within India $51 \%, 18 \%, 15 \%$ and $3 \%$ of publications in predatory journals are published by second level academic institutes, state and central universities in India, respectively. This is a challenging task for UGC to identify such publications/journals because it considers publishing research papers in ISSN numbered journals as an eligible criterion for tenure promotions, appointments of teachers and other academic staff in universities and colleges in India. However, most predatory journals are also ISSN numbered. The present study also supports the claim of Raju $^{12}$, that ever since academic performance indicators became the major criterion for appointments and tenure promotions, the number of research papers published by teachers working in universities and colleges across India in predatory journals has increased.

\section{What if lethargy of evaluators makes a pitfall?}

Researchers from national institutes of India have also published in predatory journals (about 11\%). Figure 3 illustrates the distribution of corresponding authors across various national institutes of India. The authors of these national institutes have acknowledged research grants from the Government of India. We documented 112 research grants in the predatory publications and this raises questions on the credibility of how funding agencies are monitoring the quality of the research projects 
they are funding and also whether the funding agencies check 'what' is published and whether the published results are worthy. (For example; an acknowledgement in two predatory publications cites their funded project by Government of India as: (1) 'The authors are grateful to All India Coordinated Research Project on Post Harvest Technology, ICAR, India for financial support'. (2) 'Author is thankful to Department of Science and Technology (DST), New Delhi for funding the project (Grant no.), and University Grants Commission (UGC), New Delhi for project (Grant no.)'.

\section{Why is India among the biggest contributors of predatory articles?}

Figures 4 and 5 show the distribution of 480 respondents across different academic disciplines and academic positions. From these we found that $57 \%$ of researchers are unaware of predatory journals and $40 \%$ recognize predatory OA publishing. Further, only $20 \%$ of the respondents agree that they have published in predatory journals unknowingly. Nevertheless, $80 \%$ of the corresponding authors responded as they are aware and unaware of predatory journals are not willing/accept to answer if they have published in predatory journals themselves (Figure 6). This suggests that the authors with predatory publications are well aware about predatory OA publishing, but do not want to accept that they have published in such type of OA journals. Moreover, we agree with Shen and Björk ${ }^{11}$ that: 'most authors are not necessarily tricked into publishing in predatory journals; they probably submit to them well aware of the circumstances and take a calculated risk that experts who evaluate their publication lists

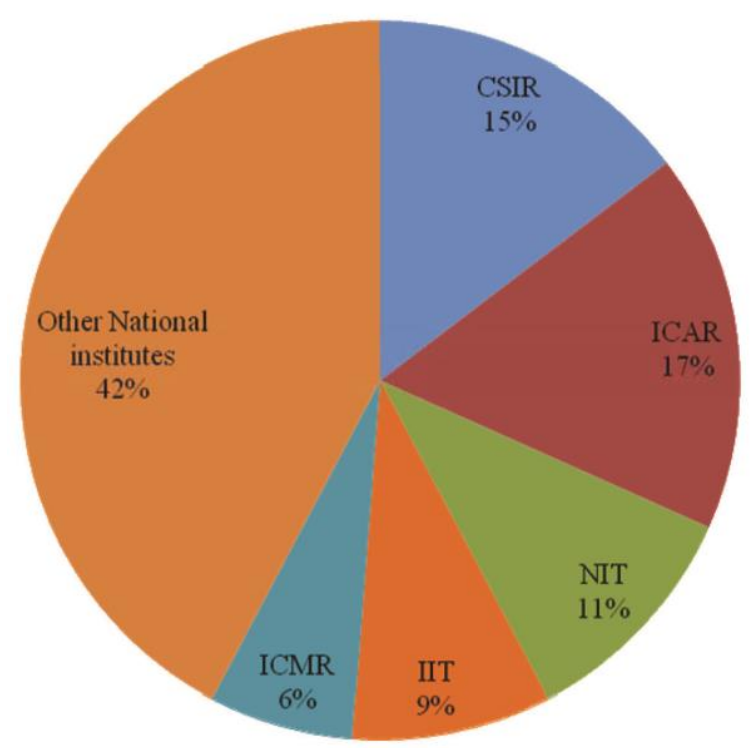

Figure 3. Distribution of corresponding authors in predatory journals from various national institutes of India. will not bother to check the journal credentials in detail. Hence we do not uncritically see the authors as unknowing victims'.

All the respondents agreed that they know about OA journals and have published in them by paying article processing charges (i.e. pay for publication either from a research grant, institutional funds, or authors' own resources). Also, $90 \%$ of the authors agreed they paid the article processing charges from their own pocket and not through research grants or institutional funds (Figure 6).

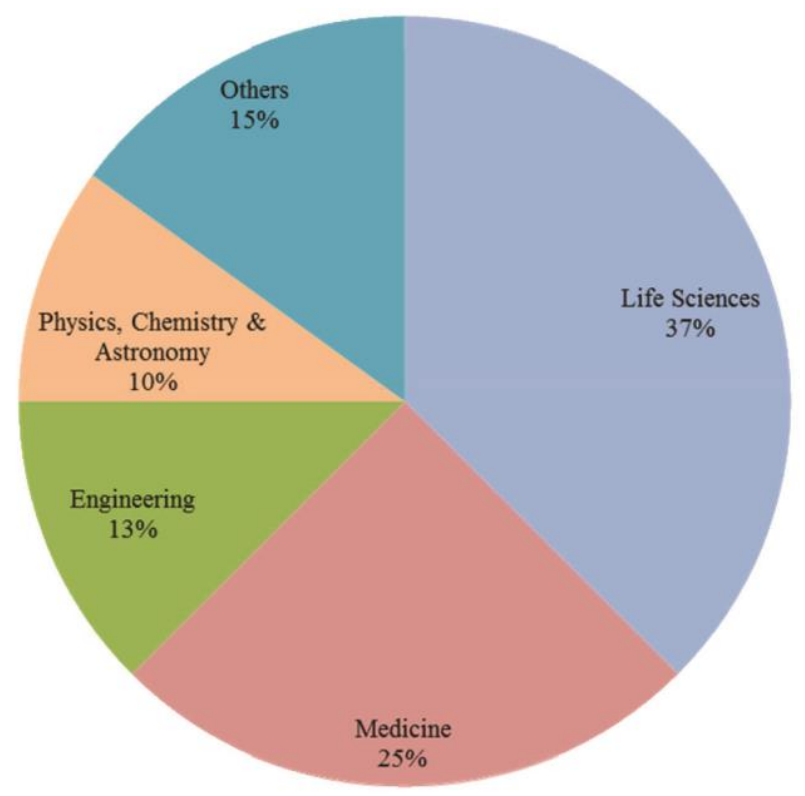

Figure 4. Academic discipline of corresponding authors in predatory journals.

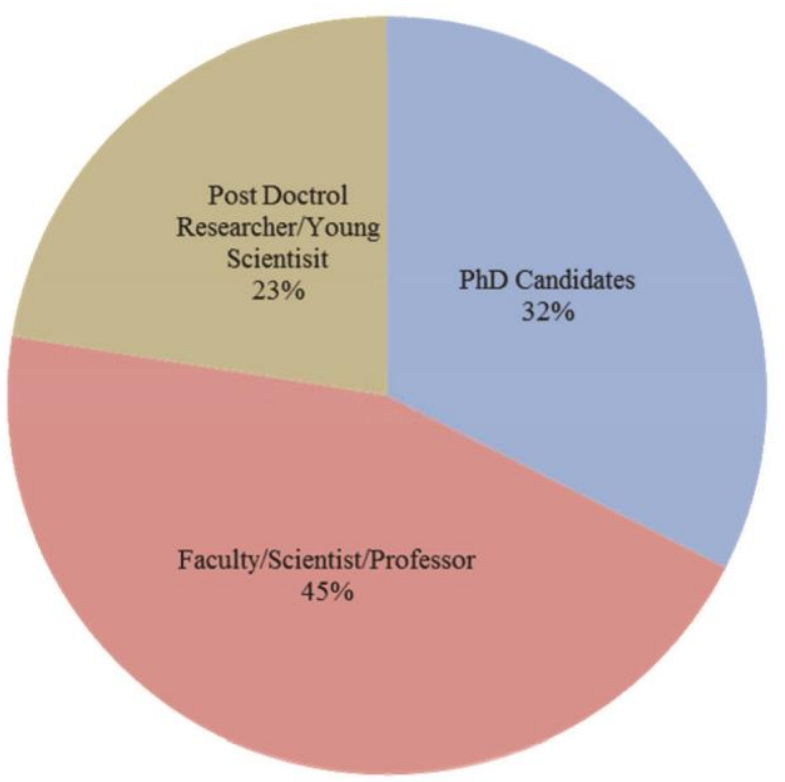

Figure 5. Academic position of corresponding authors having predatory publications who responded to the on-line questionnaire.

CURRENT SCIENCE, VOL. 111, NO. 11, 10 DECEMBER 2016 


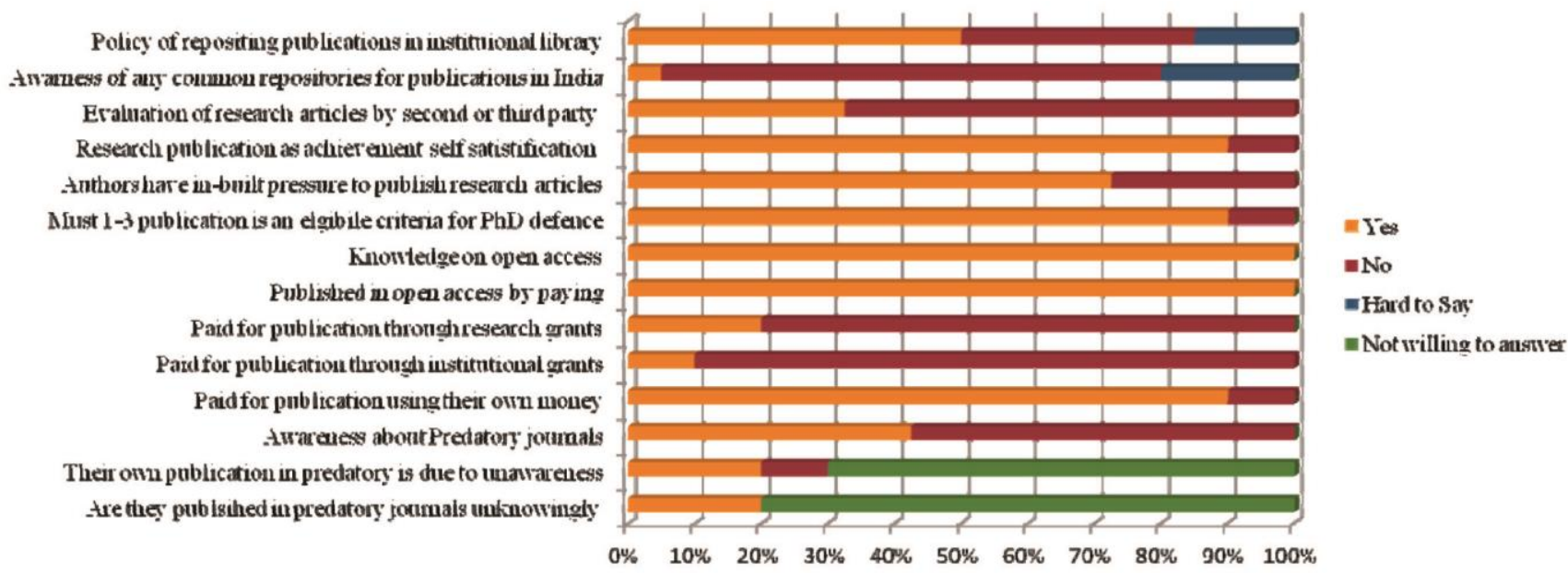

Figure 6. Key questions used in the on-line survey and percentage of responses for each question illustrated using $100 \%$ stack bar chart.

Eighty-seven per cent of publications in predatory journals are by second-level academic institutes, state and central universities. It is a known fact that science education, infrastructure of basic laboratories and funding for scientific research are not uniform across all layers of the higher educational and research institutes in India ${ }^{13}$. Also, the country's public research is highly concentrated only in national research centres. This suggests that researchers at these second-level academic institutes with poor infrastructure and laboratory facilities are carrying out preliminary research in their small laboratories and publishing their research data in predatory journals.

One of the reasons for Indian academicians and researchers to publish in predatory journals is publication pressure on young researchers who are in the search of a permanent academic position ${ }^{14,15}$. In our survey, $90 \%$ and $73 \%$ of authors considered research publication as an achievement and has academic pressure respectively to publish research articles because publication gives job securities and promotions (Figure 6).

In most academic appointments/promotions, there is emphasis on the number of publications and where they published (international or national journals) ${ }^{15}$. Most guidelines are also tailor-made in such a way that the number of publications is the major criterion for appointments and tenure promotions, and not their quality. As a consequence, publication has become the mantra and motto for academics, resulting in the rise of predatory publishing ${ }^{15,16}$. Also, a PhD student's primary objective is to publish research articles to be eligible to submit his/her PhD thesis. Our survey (90\% respondents) has confirmed that publishing 1-3 research articles is an eligible criterion for graduation, which puts pressure on the $\mathrm{PhD}$ candidates to just publish something (Figure 6). Hence, we suggest that higher educational institutes in India may consider other alternatives as eligible criteria for $\mathrm{Ph} \mathrm{D}$ candidates to defend their thesis.

\section{Open access policy in India}

India ranks 10th in the world for output of scientific papers (sadly, it ranks 166th for average citations per paper; see http://www.scimagojr.com/countryrank.php). This leads to the question: are all these papers open to the public within India to read, for assessment and to build upon? Since funds disbursed by the Government of India (GoI) are public funds, it must be ensured that the information and knowledge generated through the use of public funds are made available to the public. As an initiative to make all knowledge publically available, the Department of Biotechnology (DBT) and Department of Science and Technology (DST), constituent departments within the Ministry of Science and Technology, GoI have created two central repositories - IR@DST(http://dst.science-central. in/) and IR@DBT(http://dbt.sciencecentral.in/) aimed at creating many institutional repositories.

DBT and DST jointly released a document on 12 December 2014 entitled 'DBT and DST Open Access Policy', highlighting 'Open Access awareness initiatives' and that every year DBT and DST institutes will celebrate 'Open Access Day' during the International Open Access Week (http://www.openaccessweek.org/) by organizing lectures, programmes, workshops and taking new OA initiatives. However, in the survey we found that only $5 \%$ of authors are aware of common repositories in India like UGC's Information and Library Network (INFLIBNET) and Shodhganga, INFLIBNET Centre. Further the document informs that DBT and DST recognize the right of researchers to publish their work in journals of their choice, because researchers are the best judges of where to publish their work. In the survey, we found that $20 \%$ and $10 \%$ of the authors availed research grants and institutional grant to pay for publication in OA predatory journals (Figure 6); this contradicts the above statement. Since $11 \%$ of authors publishing in predatory journals are 
from national institutes, they might have paid article processing charges using their research grants or institutional grants to publish in OA predatory journals. If DBT, DST, and UGC's open access repositories do not set any criteria as basic requirements to journals and publications, it poses a serious threat and questions whether publications in poor-quality journals can also be submitted to such repositories? We have documented 112 research grants acknowledged by authors in their publications in predatory journals, which leads to the question whether these articles were submitted to such repositories, and if so, were they scrutinized for quality?

In the survey we asked, 'does your institute have the policy of depositing all your faculty publications in library repository' (so that all faculty publications are available to anyone using the library)? We found $50 \%$, $35 \%$ and $15 \%$ of authors say yes, no and not sure respectively. This suggests that although $50 \%$ of authors deposit their publication in the library, it does not reflect whether the submitted articles are being critically evaluated by any committees within their institutes for credibility to be deposited in the library. Therefore, we propose that all Indian higher educational institute libraries should have an OA repository which contains all their faculty publications (i.e. self-archiving or 'green' OA). Having such policies in each institute will help monitor own publications under the set rules and regulations. Also, the general public and others researchers can access publications made by various institutes.

\section{Conclusion}

From the present quantitative study it is evident that India is lacking in monitoring the research being conducted at different higher educational and research institutes. Thus there is an urgent need to develop a mechanism both by institutes and funding agencies to identify the quality of the articles published by the respective institutes and researchers. Also, researchers with enough scientific passion at second-level educational institutes should be encouraged to improve their quality of research and submit their publications to recognized scientific peerreviewed journals.

1. https://arts.st-andrews.ac.uk/philosophicaltransactions/ (accessed 14 February 2016).
2. Cope, B. and Phillips, A., The Future of the Academic Journal, Elsevier Science, Burlington, MA, USA, 2014, pp. 1-2.

3. Bergstrom, C. T. and Bergstrom, T. C., Nature Publishing Group, Can 'author pays' journals compete with 'reader pays'? http:// www.nature.com/nature/focus/accessdebate/22.html (accessed 18 December 2015).

4. Kozak, M. and Hartley, J., Publication fees for open access journals: different disciplines - different methods. J. Assoc. Inf. Sci., 2013, 64(12), 2591-2594

5. Butler, D., The dark side of publishing. Nature, 2013, 495(7442), 433-435.

6. Beall, J., Predatory publishers are corrupting open access. Nature, 2012, 489(7415), 179.

7. Beall, J., Criteria for determining predatory open-access publishers. Scholarly Open Access; 2015; https://scholarlyoa.files. wordpress.com/2012/11/criteria-2012-2.pdf (accessed 18 November 2015).

8. Kogleck, L., Priyadarshini, S., Pincock, S., Bocquet, A. and Gilloch, C., Nature Index analysis 2014: India's ascent towards world-class science, 2015; http://www.natureindex.com/news/indianscience-ascending (accessed 18 December 2015).

9. Bohannon, J., Who's afraid of peer review? Science, 2013, 342, 60-65.

10. Xia, J., Harmon, J. L., Connolly, K. G., Donnelly, R. M., Anderson, M. R. and Howard, H. A., Who publishes in 'predatory' journals? J. Assoc. Inf. Sci., 2014, 66, 1406-1417.

11. Shen, C. and Björk, B. C., 'Predatory' open access: a longitudinal study of article volumes and market characteristics. BMC Med., 2015, 13(1), 1 .

12. Raju, N. V., How does UGC identify predatory journals? Curr. Sci., 2013, 104(11), 1461-1462.

13. Nature Publishing Group, Challenges for science in India. Nature Mater., 2009, 8, 361.

14. Raghavan, R., Dahanukar, N. and Molur, S., Curbing academic predators: JoTT's policy regarding citation of publications from predatory journals. J. Threat. Taxa., 2015, 7(10), 7609-7611.

15. Gad-el-Hak, M., Publish or perish - an ailing enterprise? Phys. Today, 2004, 57(3), 61-64.

16. Lakhotia, S. C., Predatory journals and academic pollution. Curr. Sci., 2015, 108(8), 1407-1408.

ACKNOWLEDGEMENTS. We thank Cenyu Shen (Hanken School of Economics Helsinki, Finland), Ingvild Austarheim and Helle Wangensteen (University of Oslo, Norway) for their support and active discussions during the course of this work. We also thank all the respondents to our questionnaire and the anonymous reviewer for suggestions that helped to improve the manuscript.

Received 17 February 2016; revised accepted 1 August 2016

doi: $10.18520 / \mathrm{cs} / \mathrm{v} 111 / \mathrm{i} 11 / 1759-1764$ 